\title{
Diagnosing the service quality improvement of university libraries in intuitionistic fuzzy environment
}

\author{
Hossein Sayyadi Tooranloo ${ }^{1}$, Arezoo Sadat Ayatollah², \\ and Mahtab Tavangar Marvasti ${ }^{3}$ \\ ${ }^{1}$ Faculty of Management, Vali-e-Asr University of Rafsanjan, Rafsanjan, IRAN \\ ${ }^{2}$ Faculty of Information Technology Management, \\ University of Science and Arts, Yazd, IRAN \\ ${ }^{3}$ Faculty of Industrial Management, University of Science and Arts, Yazd, IRAN \\ e-mail: h.sayyadi@vru.ac.ir (corresponding author); as.ayatollah@stu.sau.ac.ir; \\ m.tavangar@stu.sau.ac.ir
}

\begin{abstract}
Libraries and information centres are service organizations connecting academic communities to knowledge and information through efficient services as their main mission. Given the importance of high-quality services in libraries and increased users' demand for receiving better service, the promotion of service quality levels is as one of the crucial challenges of libraries. This study is an attempt to provide a model for diagnosis of library service quality using Failure Modes and Effects Analysis (FMEA) approach in an intuitionistic fuzzy environment. The proposed model is applied in libraries of Yazd University of Science and Art in Iran. Accordingly, 25 failure items of library service quality in library services are first determined for diagnosis through reviewing the literature and interviewing the academic experts, as well as library managers at Yazd University of Science and Art. Following the determination of these items, a questionnaire was administered to the experts. The results indicate that "the lack of appropriate social spaces for group learning and study" is an item of highest priority in quality improvement of library service. The results of this research can be used to guide managers and decision makers in order to plan for improving the quality of library services.
\end{abstract}

Keywords: Service quality; LibQUAL assessment model; University Libraries; Failure Modes and Effects Analysis (FMEA); Intuitionistic Fuzzy

\section{INTRODUCTION}

Nowadays, people live in an environment that increasingly proceeds towards a servicebased economy. Service is not a small part of an economy any longer, but it is considered as the heart of value creation in the economy. The service sector has the largest share in the economy of countries (William 2005). Due to the importance of the service sector, the Service Quality Excellence is thus significantly important in this sector, So that providing quality services is one of the most important challenges of this century in service organizations. (Kang, Jame and Alexandris 2002).

As service organizations, libraries play a vital role in the sustainable development process of countries. Therefore, it could be claimed that this development is unachievable without 
strong and credible libraries and information centres (Lin, Chiu and Chu 2006). Library and information centre managers are increasingly faced with a wide range of user demands for faster and more effective service. This issue, with the inability to collect all or even some of the information, and the Increasing the costs of magazine subscriptions, has caused them to pay attention to the provision of information sources rather than the provision of case and locative (Eddy and Solomon 2017). Given the importance of service quality in libraries and increasing user demand for better services, the service quality improvement is one of the major issues in libraries. Library managers seek to provide infrastructures for achievement of high quality library services by focusing on customers' needs and appropriate response to their demands (Uddin and Khandakar 2013).

Studies indicate that the service quality improvement yields valuable results for organizations, and ultimately leads to customer satisfaction and loyalty, more market share, and higher profitability for the organizations. Even though profitability is not the main objective of non-profit organizations, the quality level improvement will increase user satisfaction (Bell and Eisingrich 2007). Library service quality includes special service features, which meet customer expectations; and it is compatible with customers' needs (Mirghafuri and Makki 2007). In this regard, LibQUAL service quality measurement model is among the most reputable library evaluation models according to the efficiency of libraries with an approach to service quality provision for customers (Garthwait and Richardson 2008). This model focuses on the existing status of quality elements of libraries, and eventually, using gap analysis, identifies the most important elements that can improve quality. However, a more appropriate approach can prevent the creation of quality errors in the system that may cause the drop in quality, threaten loyalty and commitment of current customers, and stop their use of library services. These errors, which are considered as a failure to meet the appropriate quality level, should be thus detected and evaluated by systematic and scientific methods, so that the qualitative improvement will safely pass its most critical phase (Lin, Chiu and Chu 2006).

The matter of great importance in the assessment process of LibQUAL model is that its measures are expressed as subjective, qualitative and verbal variables; therefore, the evaluation of aspects and indicators of LibQUAL model by means of non-fuzzy and deterministic ways could be criticized for the following reasons (Lin, Chiu and Chu 2006):

(a) The aforementioned procedures overlook the uncertainties associated with judgments of people and ignore the changes in their value as they are transmitted to numbers;

(b) Mental judgments, selection and prioritization of evaluators have a great influence on the results of these methods.

Fuzzy logic may provide a useful tool to deal with ambiguous issues. By using fuzzy concepts, evaluators could use verbal expressions as colloquial language to evaluate the service quality indices and apply more appropriate and precise analyses on the scores obtained for the respective indices by relating these expressions to appropriate membership functions. However, as the decision-making issues and affairs become more intricate, the uncertainty of issues may be subsequently increased and there is a need for more comprehensive and powerful tools than Fuzzy Set Theory (Chen and Li 2011; Deschrijver, Cornelis and Kerre 2004; Park et al. 2011; Tan 2011; Wu and Zhang 2011). By extending the fuzzy sets, Atanassov (1986) introduced intuitionistic fuzzy set theory. Intuitionistic fuzzy set theory drew high attention after its emergence (Zhao and Wei 2013) and it has become an extremely useful as well as an effective tool to deal with uncertainties (Park, Cho and Kwun 2013). Moreover, using intuitionistic fuzzy set theory in 
evaluations that are based on experts' comments, we may provide more precise results compared to deterministic and fuzzy sets. This paper investigates one of the applications of this theory in the area of decision-making issue and the method of dealing with extant uncertainties in these issues. Furthermore, a new intuitive fuzzy multi-criteria decision making method with Failure Modes and Effects Analysis (FMEA) approach, as well as a new method by using intuitionistic fuzzy TOPSIS technique, are used to evaluate the failure items of library service quality.

\section{LITERATURE REVIEW}

The library, as an institution and service organization, is required to implement successful strategies, inspiring from the business world, to serve the customers. Many libraries are currently providing round-the-clock required facilities and digital access to information for their customers (Miao and Bassham 2007). Service in library is an essential concept, and libraries as the centres of innovation, information, and culture, play crucial roles in learning during the customers' lifetime. Therefore, sufficient attention to libraries through important and appropriate standards is a matter of great importance. End users are considered as the customers of this very system and the focus of library service is upon them. Evaluation the library service quality provides important feedback to further improve library services to users (Filiz 2007). The investigations indicate that the service quality improvement provides worthy results to organizations and ultimately leads to the customers' loyalty and satisfaction, acquisition of more market share, and finally more productivity for the organizations (Bell and Eisingerich 2007). Though productivity is not considered as a main purpose of public sector organizations, e.g. public libraries, the promoted quality level may lead to increased satisfaction. Evaluation of service quality in libraries is a matter of special importance for high quality libraries because it may facilitate the process of sustainable development in countries.

In the past, the quality of libraries was evaluated according to the size of sets, the variation of books and journals, and the number of users; however, it has long been discussed to involve users in the process of evaluation to provide more acceptable and valid results (Zabed and Shoeb 2009). Currently, there are ever-increasing pressures on the libraries to set their performance appraisal mostly based on the result-oriented criteria rather than the data and resources evaluation indices. In other words, the performance of a library is based on the provision level of qualitative services for customers; hence, such a criterion indicates the efficiency and effectiveness of a library (Lane et al. 2012).

Quality is the philosophy and the fundamental requirement of library service. Service quality of a library means precisely, accurately, completely, and rapidly responding to each user needs (Sharma 2001). In addition to easy access to library and information, guiding and helping customers are also included in services provided by the library (Gupta and Ashok 2002). Therefore, regarding the important role of libraries, the evaluation of performance quality is also a matter of great importance. Various models are presented by experts to evaluate the quality in service organizations. The LibQUAL model is one of the most well -known models presented by these scholars.

\section{LibQUAL Model}

In the twenty-first century, libraries are increasingly faced with display of their impact. Academic libraries have faced their biggest challenge in recent years. This challenge started since the explosion of academic publications (after the World War II) and intensified by 
emergence of virtual libraries. Therefore, the Association of Research Libraries (ARL) supports a number of innovative evaluation tools. These tools attempt to display an overview of libraries based on its collection, the service quality and users' satisfaction. LibQUAL model is one of these new tools. This model is based on the users' perspective and a way to listen to user feedback (Stephen 2005).

Some library and information researchers have presented appropriate and specialized tools to analyze the extant gap in library services. Based on the various interview with library users, the aforementioned measures led to restructured SERVQUAL tool; accordingly, LibQUAL as the specialized tool for the quality assessment of libraries, was developed, tested, and modified by the Association of Research Libraries (ARL 2003; 2004; 2006). LibQUAL tools was developed based on the SERVQUAL technique for evaluating the quality of services in libraries (Miao and Bassham 2007). LibQUAL is a tool based on which libraries could receive the comments and expectations of customers in terms of the library services, and also appraises and subsequently improves the services as well (Roy et al. 2012). This model aims at identifying and analyzing the gap between customers' expectations and their perceptions through identifying the most important criteria of service quality (Lin, Chiu and Chu 2006).

LibQUAL model is developed cooperatively by the Association of Research Libraries and Texas A\&M University in 1999. This model is based on the comments made by users and is a tool to listen the customers' views (Cook, Heath and Thompson 2003). LibQUAL model aims at measuring the gap between expected and received services in specific dimensions (Cook and Heath, 2001; Scherrer and Jacobson 2002). This model seeks to achieve the following important goals (Cook and Heath 2001):

(a) Helping the libraries to better understand the customers' expectations of service quality,

(b) Collecting and interpreting the library users' feedback regularly over time,

(c) Recognizing the best procedure to provide services.

The standard questionnaire of this model consists of 22 items asking users to present their minimum levels of expectation, their maximum levels of expectation and their perception of received library services in three separated columns based on a 9-point Likert scale. Scores 1 and 9 refer to the least and highest levels respectively (Thompson, Cook and Kyrillidou 2005). In this questionnaire, the first 9 items deal with effectiveness aspect of services (i.e. interaction between librarians and users), the succeeding 8 items deal with information control aspect (i.e. the user's ability to find information), and the last 5 statements deal with library as a place (i.e. the physical environment of library).

LibQUAL method may enable the professional management of academic libraries, recognition of strengths and weaknesses, contribution to planning and decision making, service development, change apply, approach to users' needs, comparison of a library performance with others, and finally the selection of best measure (de Brito and Vergueiro 2013). The aforementioned tool is widely used in this area, so that the data associated with users' expectations and their perceptions of received services was collected from approximately 340,000 users in more than 500 organizations by 2005 . In addition to USA, Canada, Australia, England, Ireland and Scotland, LibQUAL tool has been used in various countries with different languages as well (Thompson, Cook and Kyrillidou 2005).

There are studies conducted on LibQUAL model; some of these studies are summarized as follows. In 2003, 2004, and 2005, Godwin dealt with evaluating 20 libraries dependent to London South Bank University based on LibQUAL model. The results reveal that service 
quality had a higher level in 2005 compared to two years earlier; moreover, the results indicate that libraries have better performance in service effectiveness aspect than other aspects (Godwin 2005). Feather conducted a study on the quality evaluation of libraries at Ohio State University during 2002, 2003, and 2005 years by using LibQUAL model (Feather 2005). Kyrillindou and Persson implemented LibQUAL model at Lund University, Sweden. Their findings refer to the fact that information control aspect has a high priority for users; however, the under-study libraries have failed to meet the users' expected needs in this area. In this study, LibQUAL is known by users as a new evaluation tool assessing the expectations beyond the traditional tools (Kyrillindou and Persson 2006). In another research project, Cook implemented the LibQUAL model in Texas libraries. The results show that the level of received library services in information control aspect is higher than the maximum level of users' expectations (Cook and Colleen 2006). Thompson, Kyrillidou and Cook (2007), in their study entitled "user expectations of library services" dealt with implementing LibQUAL model. Their study aims at discovering the differences between 2004, 2005, and 2006, and USA and Britain, and also the differences between three groups of users, namely bachelor, master and Ph.D. degree students. The results indicate that the users' satisfaction levels with service quality of respective library follow an increasing trend during three aforementioned years (Thompson, Kyrillidou and Cook 2007). Using LibQUAL model, Jones and Kayongo dealt with investigating the users' satisfaction and compare the internal results and those obtained from members at libraries of Association of Research Libraries. By exact investigation of information control indicators of LibQUAL from faculty members' perspective, the aforementioned research promotes the awareness of library of the faculty members' key needs and clarifies the areas in information control indicator which are required to be improved (Kayongo and Jones 2008). Jaggars, Jaggars and Duffy (2009) in their study entitled "Comparing Service Priorities between Staff and Users in ARL Member Libraries" also used LibQUAL model. The results indicate an essential difference in comments made by users and those made by staff. The library staff put the information control on a lower priority compared to the library users; furthermore, the staff considered the service effectiveness in a higher priority compared to users (Jaggars, Jaggars and Duffy 2009).

Ladhari and Morales (2008) in their research entitled "The study of public library users in Canada", aimed at presenting a conceptual as well as empirical model expressing the relation among the quality of received services, the effectiveness of received services, and recommendations in terms of public libraries. In this study, LibQUAL tool is used as the data collection method. To this end, the given tool was distributed among 439 users of public libraries in Canada. The findings indicate that the effectiveness of services, library as a place, and information control aspects significantly represent the effectiveness of received services. There was a strong relation between effectiveness of received services and the users' recommendations. The results also indicate the validity of LibQUAL tool in this study, reflecting the appropriate relevance of this tool to the context of services in public libraries (Ladhari and Morales 2008). Posey (2009) conducted a study with the aim of recognizing the students' expectations and their levels of satisfaction with service quality of libraries in Walter Stace's School of Communication. In this study, LibQUAL is used as the selected tool to collect data. A total of 666 students' responses at Walter Stace's School of Communication, Moorestown, indicate the minimum levels of services and received level and the minimum expected level of library services as well. The findings indicated that the score of library at Walter Stace's School of Communication in LibQUAL aspects was higher than the other four libraries at Communication schools. The scores obtained from the comments made by male and female students at the respective faculty indicated no difference between them in term of service quality aspect. Findings also 
indicate the fact that the average score assigned to effectiveness of received services and information control aspects by the new students was higher than the average score obtained from older students. Furthermore, the results showed a strong relation between library budget and information control aspect (Posey 2009).

\section{Fuzzy Failure Modes and Effects Analysis (FMEA)}

Fuzzy FMEA provides a tool that works best with vague concepts and lack of sufficient information (Daniela and Dosoinescu 2004). Using fuzzy theory is essential when dealing with some degree of uncertainty in relationships among various criteria or when relations cannot be expressed in the form of definite numbers. Fuzzy FMEA has been applied by several earlier studies to assess risk (Chanamool and Naenna 2016). For example, Chang and colleagues used grey theory for FMEA. Their study first used fuzzy expressions such as very low, low, medium, high and very high to evaluate severity (S) and detection (D), occurrence $(\mathrm{O})$, and then applied grey relational analysis to determine the risk ratings of potential causes. By performing the grey relational analysis, fuzzy expressions were converted to definitive values, and the lowest levels of $O, S$ and $D$ were defined as the standard series. Data regarding these three factors for each potential cause were seen as comparative series and grey relational coefficients and degree of grey relation were compared against the standard series under the rules of grey theory. The highest degree of grey relation indicated minimal effect of potential cause (Chang, Wei and Lee 1999).

Braglia, Frosolini and Montanari (2003) also proposed a multi-criteria decision making approach called fuzzy TOPSIS for FMEA. As a well-known multi-criteria decision-making method, TOPSIS is based on the idea that the best decision should have minimum distance from the positive ideal and maximum distance from the negative ideal. The fuzzy TOPSIS approach provides the possibility of evaluating risk factors $(\mathrm{O}, \mathrm{S}$ and $\mathrm{D})$ and their relative importance using triangular fuzzy numbers (Braglia, Frosolini and Montanari 2003). Bowles and Peláez (1995) proposed a fuzzy logic-based approach to prioritize failures in a FMEA system. This approach used verbal expressions to describe $O, S, D$ and the risks of failure. The relationships between risk and $O, S, D$ were described using fuzzy if-then rules obtained from experts' opinion. Garcia, Schirru and Melo (2005) proposed a fuzzy data envelopment analysis approach combined with fuzzy sets to determine the rating of failure modes (Garcia, Schirru and Melo 2005). Chen and Kuo (2009) calculated fuzzy risk priority number (RPN) by using fuzzy ordered weighted geometric averaging (FOWGA) operator. Similarly, Wang et al. proposed a new definition for fuzzy RPN by using fuzzy weighted geometric mean (FWGM).

Fuzzy RPN can also be calculated using alpha-cut sets, linear programming model and defuzzification through centre of gravity method, to obtain the final ranking of failure modes (Wang et al. 2009). Kutlu and Ekmekcioglu (2012) proposed a hybrid approach based on TOPSIS and analytic hierarchy process (AHP) in a fuzzy setup to analyze failure modes. Their study used the fuzzy AHP method to determine the weight of risk factors. After assigning the weights and generating the failure items decision matrix for risk factors, fuzzy TOPSIS was performed to prioritize the failure modes. The study by Liu et al. (2012) developed a model based on fuzzy VIKOR techniques to assess and prioritize risk factors. It used linguistic terms and corresponding fuzzy numbers to determine the weight of risk factors based on expert opinions. Then, the fuzzy ordered weighted decision matrix for factors of failure modes was calculated and the VIKOR technique was used to prioritize failure modes. In another attempt, Kumru and Kumru (2013) investigated the applications of fuzzy FMEA to improve procurement processes of a hospital. They concluded that fuzzy FMEA technique could properly solve problems associated with traditional FMEA and could 
be useful for exploring potential failure modes and their effects. Finally, the study by Rafie and Namin (2015) proposed a hybrid approach comprising fuzzy rules and neural network to evaluate the RPN in FMEA. It used fuzzy rules to determine severity (S) and detection $(D)$, occurrence $(O)$ was determined using neural network.

\section{Intuitionistic Fuzzy Set (IFS)}

Intuitionistic fuzzy set (IFS) is one of the generalizations from the fuzzy sets theory (Zadeh 1965). Out of several higher-order fuzzy sets, IFS has been found to be more capable of dealing with vagueness. First introduced by Atanassov (1983), IFS may be viewed as an alternative approach to conventional fuzzy set in dealing with cases with insufficient information. Fuzzy sets only consider the degree of acceptance, whereas IFS is characterized by both a membership function and a non-membership function so that the sum of both values is less than one (Atanassov 1986). Intuitionistic fuzzy sets have been used across different scientific fields, including in the studies by Atanassov (1986, 1989, 1999, 2000), Atanassov and Gargov (1989), Buhaescu (1989), Ban (2006), Deschrijver and Kerre (2002), Stoyanova (1993) and Szmidt and Kacprzyk (2000).

Definition 1: Assume reference set $X=\left\{x_{1}, x_{2}, x_{3}, \ldots\right\}$. In this case, set $\mathrm{A}$ which is a subset of $\mathrm{X}$ is an Atanassov's intuitionistic fuzzy set defined as below:

$$
A=\left\{\prec x, u_{A}(x), v_{A}(x) \succ \forall x \in X\right\}
$$

In the above definition, $u_{A}(x), v_{A}(x)$ are degree of membership and non-membership respectively, which are defined as $u_{A}(x): x \rightarrow[0,1], v_{A}(x): x \rightarrow[0,1]$ and satisfy $0 \leq u_{i j}(x)+v_{i j}(x) \leq 1$. In addition, for each $x \in X$, intuitionistic index $\pi_{x}$ is defined as $\pi_{x}=1-u_{x}-v_{x}$ (Atanassov 1986).

Definition 2: Based on Atanassov $\left(u_{i j}(x), v_{i j}(x), \pi_{i j}(x)\right)$ is an intuitionistic fuzzy number that satisfies the following conditions:

$$
\mu_{i j}(x) \in[0,1], v_{i j}(x) \in[0,1], \pi_{i j}(x) \in[0,1], 0 \leq \mu_{i j}(x)+v_{i j}(x) \leq 1, \pi_{i j}(x)=1-\mu_{i j}(x)-v_{i j}(x)(2)
$$

Although intuitionistic fuzzy number is similar (in appearance) to triangular fuzzy number $(a, b, c)$, it is quite different. Triangular fuzzy number is a convex normal fuzzy set with a membership function in which $(a \prec b \prec c)$, whereas an intuitionistic fuzzy number is a point in three-dimensional space constructed by axes $u_{i j}(x), v_{i j}(x), \pi_{i j}(x)$ (Szmidt and Kacprzyk 2001). Atanassov and Gargov (1989) and Gau and Buehrer (1993) have described intuitionistic fuzzy number $(0.50,0.20,0.30)$ as a scenario where votes in favor of adoption are 0.5 , votes against it are 0.2 and abstained votes are 0.30 . In this context, the following relationship holds true:

$$
\mu_{i j}^{\beta}(x)+v_{i j}^{\beta}(x) \leq 1,0 \leq \mu_{i j}^{\alpha}(x) \leq \mu_{i j}^{\beta}(x) \leq 1,0 \leq v_{i j}^{\alpha}(x) \leq v_{i j}^{\beta}(x) \leq 1
$$

These numbers are better suited to deal with uncertainty and provide a more logical mathematical framework to deal with inexact facts and incomplete information (Zhang et al. 2010). Some of the operators and relationships between these numbers are provided as 
the following. For simplicity's sake, these numbers are expressed as $\left[u_{i j}(x), v_{i j}(x), \pi_{i j}(x)\right]$ where $u_{i j}(x)$ are numbers in the range of $[0,1] . \pi_{i j}(x)$ and $v_{i j}(x)$.

Definition 3: Assume intuitionistic fuzzy numbers

$A=\left\{\left\langle x, \mu_{A}(x), v_{A}(x) \mid x \in X\right\rangle\right\}, A_{1}=\left\{\left\langle x, \mu_{A_{1}}(x), v_{A_{1}}(x) \mid x \in X\right\rangle\right\}$,

$A_{2}=\left\{\left\langle x, \mu_{A_{2}}(x), v_{A_{2}}(x) \mid x \in X\right\rangle\right\}$, and the real number $n$. According to De, Biswas and Roy (2000) and (Atanassov 1986) the following relationships are defined:

$$
\begin{aligned}
& \bar{A}=\left\{\left\langle x, v_{A}(x), \mu_{A}(x) \mid x \in X\right\rangle\right\} \\
& A_{1} \cap A_{2}=\left\{\left\langle x, \min \left\{\mu_{A_{1}}(x), \mu_{A_{2}}(x)\right\}, \max \left\{v_{A_{1}}(x), v_{A_{2}}(x)\right\} \mid x \in X\right\rangle\right\} \\
& A_{1} \cup A_{2}=\left\{\left\langle x, \max \left\{\mu_{A_{1}}(x), \mu_{A_{2}}(x)\right\}, \min \left\{v_{A_{1}}(x), v_{A_{2}}(x)\right\} \mid x \in X\right\rangle\right\} \\
& A_{1}+A_{2}=\left\{\left\langle x, \mu_{A_{1}}(x)+\mu_{A_{2}}(x)-\mu_{A_{1}}(x) \cdot \mu_{A_{2}}(x), v_{A_{1}}(x) \cdot v_{A_{2}}(x) \mid x \in X\right\rangle\right\} \\
& A_{1} \cdot A_{2}=\left\{\left\langle x, \mu_{A_{1}}(x) \cdot \mu_{A_{2}}(x), v_{A_{1}}(x)+v_{A_{2}}(x)-v_{A_{1}}(x) \cdot v_{A_{2}}(x) \mid x \in X\right\rangle\right\} \\
& n A=\left\{\left\langle x, 1-\left(1-\mu_{A}(x)\right)^{n},\left(v_{A}(x)\right)^{n} \mid x \in X\right\rangle\right\} \\
& A^{n}=\left\{\left\langle x,\left(\mu_{A}(x)\right)^{n}, 1-\left(1-v_{A}(x)\right)^{n} \mid x \in X\right\rangle\right\}
\end{aligned}
$$

Where $n$ is a positive integer

\section{DESIGNING A LIBQUAL ASSESSMENT MODEL ACCORDING TO THE INTUITIONISTIC FUZZY FMEA}

In the LibQUAL model, the failure to meet qualitative components can be considered as components of service quality failure in LibQUAL model. There is an extensive debate on the fact that risk factors of failure occurrence (O), severity $(S)$ and detection. (D) is not easily measurable. As the verbal evaluation by people is approximate, it can be argued that the intuitionistic fuzzy set theory is appropriate for dealing with the uncertainty of this type of evaluations and may provide results that are more precise as well. Accordingly, the present section proposes the "group decision-making model" by using TOPSIS technique to evaluate the failure items based on FMEA model in intuitionistic fuzzy environment. Table 1 demonstrates the verbal expressions and their corresponding intuitionistic fuzzy numbers used in present study to evaluate the risk factors. On this basis, suppose that there are $n$ failure items $F M_{i}(1, \ldots, n)$ evaluated by a k-expert $T M_{k}(1, \ldots, k)$, in risk factors $C=\{O, S, D\}$ based on the intuitionistic fuzzy linguistic variables included in Table 1. 
Table 1: The Intuitionistic Fuzzy Linguistic Variables

\begin{tabular}{|c|c|c|c|c|c|}
\hline \multicolumn{2}{|c|}{ Detectability } & \multicolumn{2}{|c|}{ Failure severity probability } & \multicolumn{2}{|c|}{ Failure occurrence probability } \\
\hline $\begin{array}{l}\text { Intuitionistic } \\
\text { fuzzy number }\end{array}$ & Linguistic term & $\begin{array}{l}\text { Intuitionistic } \\
\text { fuzzy number }\end{array}$ & Linguistic term & $\begin{array}{l}\text { Intuitionistic } \\
\text { fuzzy number }\end{array}$ & Linguistic term \\
\hline$(1,0)$ & $\begin{array}{l}\text { Absolutely } \\
\text { Impossible }\end{array}$ & $(1,0)$ & $\begin{array}{l}\text { Risky Without } \\
\text { Warning }\end{array}$ & $(0.9,0.1)$ & Very High \\
\hline$(0.9,0.1)$ & Highly Unlikely & $(0.9,0.1)$ & $\begin{array}{l}\text { Risky With } \\
\text { Warning }\end{array}$ & $(0.75,0.2)$ & High \\
\hline$(0.8,0.1)$ & Unlikely & $(0.8,0.1)$ & Very High & $(0.5,0.45)$ & Medium \\
\hline$(0.7,0.2)$ & Very Low & $(0.7,0.2)$ & High & $(0.35,0.6)$ & Low \\
\hline$(0.6,0.3)$ & Low & $(0.6,0.3)$ & Medium & $(0.1,0.9)$ & Very Low \\
\hline$(0.5,0.4)$ & Medium & $(0.5,0.4)$ & Low & & \\
\hline$(0.4,0.5)$ & Relatively High & $(0.4,0.5)$ & Very Low & & \\
\hline$(0.25,0.6)$ & High & $(0.25,0.6)$ & Insignificant & & \\
\hline$(0.1,0.75)$ & Very High & $(0.1,0.75)$ & Very Insignificant & & \\
\hline$(0.1,0.9)$ & $\begin{array}{l}\text { Absolutely } \\
\text { Possible }\end{array}$ & $(0.1,0.9)$ & None & & \\
\hline
\end{tabular}

The steps of intuitionistic fuzzy TOPSIS technique are presented to evaluate the failure items based on the risk factors as follows.

\section{Step 1: Determining the weights of decision makers (DMs)}

As mentioned, suppose that the decision making team is based on $\mathrm{k}$ members; the importance of each decision maker is expressed based on the verbal expressions and intuitionistic fuzzy numbers included in Table 2. Suppose that $D_{k}=\left\{\mu_{k}, v_{k}, \pi_{k}\right\}$ is an intuitionistic fuzzy number for the $k^{\text {th }}$ decision maker; then the weight of $k^{\text {th }}$ decision maker is calculated as follows:

$$
\begin{aligned}
& \lambda_{k}=\frac{\left(\mu_{k}+\pi_{k}\left(\frac{\mu_{k}}{\mu_{k}+v_{k}}\right)\right)}{\sum_{k=1}^{l}\left(\mu_{k}+\pi_{k}\left(\frac{\mu_{k}}{\mu_{k}+v_{k}}\right)\right)} \\
& \sum_{k=1}^{l} \lambda_{k}=1
\end{aligned}
$$

Step 2: Constructing the aggregated intuitionistic fuzzy decision matrix based on the decision makers' opinions

Suppose that $R^{(k)}=\left(r_{i j}^{k}\right)_{m \times n}$ is an intuitionistic fuzzy decision matrix of each DM and $\lambda=\left\{\lambda_{1}, \lambda_{2}, \lambda_{3}, \ldots, \lambda_{k}\right\}$ is the weight of each DM, and $\sum_{k=1}^{l} \lambda_{k}=1, \lambda_{k} \in[0,1]$ is true. In group decision making process, all personal decision makings are required to be aggregated in an intuitionistic fuzzy decision matrix. To this end, IFWA operator $R=\left(r_{i j}^{k}\right)_{m \times n}$ presented by $\mathrm{Xu}(2007 \mathrm{~d})$, can be used as follows: 


$$
\begin{aligned}
r_{i j} & =I F W A_{\lambda}\left(r_{i j}{ }^{(1)}, r_{i j}^{(2)}, \ldots, r_{i j}^{(l)}\right) \\
& =\lambda_{1} r_{i j}^{(1)} \oplus \lambda_{2} r_{i j}^{(2)} \oplus \lambda_{3} r_{i j}^{(3)} \oplus \ldots \oplus \lambda_{l} r_{i j}{ }^{(l)} \\
& =\left[1-\prod_{k=1}^{l}\left(1-\mu_{i j}^{(k)}\right)^{\lambda_{k}}, \prod_{k=1}^{l}\left(v_{i j}^{(k)}\right)^{\lambda_{k}}, \prod_{k=1}^{l}\left(1-\mu_{i j}^{(k)}\right)^{\lambda_{k}}-\prod_{k=1}^{l}\left(v_{i j}^{(k)}\right)^{\lambda_{k}}\right]
\end{aligned}
$$

where

$$
r_{i j}=\left(\mu_{A_{i}}\left(x_{j}\right), v_{A_{i}}\left(x_{j}\right), \pi_{A_{i}}\left(x_{j}\right)\right)(i=1,2, \ldots, m, j=1,2, \ldots, n)
$$

Aggregated intuitionistic fuzzy decision matrix is demonstrated as follows:

$$
\begin{aligned}
R & =\left[\begin{array}{ccc}
\left(\mu_{F M_{1}}(O), v_{F M_{1}}(O), \pi_{F M_{1}}(O)\right) & \left(\mu_{F M_{1}}(S), v_{F M_{1}}(S), \pi_{F M_{1}}(S)\right) & \left(\mu_{F M_{1}}(D), v_{F M_{1}}(D), \pi_{F M_{1}}(D)\right) \\
\left(\mu_{F M 2}(O), v_{F M 2}(O), \pi_{F M 2}(O)\right) & \left(\mu_{F M 2}(S), v_{F M 2}(S), \pi_{F M 2}(S)\right) & \left(\mu_{F M 2}(D), v_{F M 2}(D), \pi_{F M 2}(D)\right) \\
\left(\mu_{F M 3}(O), v_{F M 3}(O), \pi_{F M 3}(O)\right) & \left(\mu_{F M 3}(S), v_{F M 3}(S), \pi_{F M 3}(S)\right) & \left(\mu_{F M 3}(D), v_{F M}(D), \pi_{F M 3}(D)\right) \\
\vdots & \ddots & \vdots \\
\left(\mu_{F M_{n}}(O), v_{F M_{n}}(O), \pi_{F M_{n}}(O)\right) & \left(\mu_{F M_{n}}(S), v_{F M_{n}}(S), \pi_{F M_{n}}(S)\right) & \left(\mu_{F M_{n}}(D), v_{F M_{n}}(D), \pi_{F M_{n}}(D)\right)
\end{array}\right] \\
& \rightarrow\left[\begin{array}{ccc}
r_{1 O} & r_{1 S} & r_{1 D} \\
r_{2 O} & r_{2 S} & r_{2 D} \\
r_{3 O} & r_{3 S} & r_{3 D} \\
\vdots & \ddots & \vdots \\
r_{n O} & r_{n S} & r_{n D}
\end{array}\right]
\end{aligned}
$$

\section{Step 3: Determining the weights of risk factors}

According to the shortcoming of traditional FMEA in this model, the weights of risk factors are similar, so that different values for risk factors may lead to the same RPN. Therefore, the weight of each risk factor is required to be determined. Assume that each of decision makers express their own views in terms of the importance of each risk factor (i.e. O, S, D) by using verbal expressions presented in Table 1 . Provided that $w_{j}^{k}=\left(\mu_{j}^{(k)}, v_{j}^{(k)}, \pi_{j}^{(k)}\right)$ is the intuitionistic fuzzy number assigned to $J$ th criterion based on the $k$ th decision maker's view, then the weights of risk factors are calculated as follows by using IFWA operator:

$$
\begin{aligned}
w_{j} & =I F W A_{\lambda}\left(w_{j}{ }^{(1)}, w_{j}{ }^{(2)}, \ldots, w_{j}{ }^{(l)}\right) \\
& =\lambda_{1} w_{j}{ }^{(1)} \oplus \lambda_{2} w_{j}{ }^{(2)} \oplus \lambda_{3} w_{j}{ }^{(3)} \oplus \ldots \oplus \lambda_{l} w_{j}{ }^{(l)} \\
& =\left[1-\prod_{k=1}^{l}\left(1-\mu_{j}^{(k)}\right)^{\lambda_{k}}, \prod_{k=1}^{l}\left(v_{j}^{(k)}\right)^{\lambda_{k}}, \prod_{k=1}^{l}\left(1-\mu_{j}^{(k)}\right)^{\lambda_{k}}-\prod_{k=1}^{l}\left(v_{j}^{(k)}\right)^{\lambda_{k}}\right] \\
W & =\left[w_{1}, w_{2}, w_{3}, \ldots, w_{j}\right] \\
w_{j} & =\left(\mu_{j}, v_{j}, \pi_{j}\right)(j=1,2, \ldots, n)
\end{aligned}
$$

\section{Step 4: Constructing the aggregated intuitionistic fuzzy weighted matrix}

After determining the weights (w), all risk factors and aggregated intuitionistic fuzzy decision matrix, and aggregated intuitionistic fuzzy weighted matrix are obtained based on the following equation (Atanassov 1986): 


$$
\begin{aligned}
& R \otimes W=\left\{\left\langle c, \mu_{F M_{i}}(c) \cdot \mu_{W}(c), v_{F M_{i}}(c) \cdot v_{W}(c)-v_{F M_{i}}(c) \cdot v_{W}(c) \mid x \in X\right\rangle\right\} \\
& \pi_{F M_{i} W}(c)=1-v_{F M_{i}}(c)-v_{W}(c)-\mu_{F M_{i}}(c) \cdot \mu_{W}(c)+v_{F M_{i}}(c) \cdot v_{W}(c)
\end{aligned}
$$

Then, aggregated intuitionistic fuzzy weighted matrix is defined as follows:

$$
\begin{aligned}
& R=\left[\begin{array}{ccc}
\left(\mu_{F M_{1} W}(o), v_{F M_{1} W}(O), \pi_{F M_{1} W}(o)\right) & \left(\mu_{F M_{1} W}(S), v_{F M_{1} W}(S), \pi_{F M_{1} W}(S)\right) & \left(\mu_{F M_{1} W}(D), v_{F M_{1} W}(D), \pi_{F M_{1} W}(D)\right) \\
\left(\mu_{F M 2 W}(o), v_{F M 2 W}(O), \pi_{F M 2 W}(o)\right) & \left(\mu_{F M 2 W}(S), v_{F M 2 W}(S), \pi_{F M 2 W}(S)\right) & \left(\mu_{F M 2 W}(D), v_{F M 2 W}(D), \pi_{F M 2 W}(D)\right) \\
\left(\mu_{F M 3 W}(O), v_{F M 3 W}(O), \pi_{F M 3 W}(O)\right) & \left(\mu_{F M 3 W}(S), v_{F M 3 W}(S), \pi_{F M 3 W}(S)\right) & \left(\mu_{F M 3 W}(D), v_{F M 3 W}(D), \pi_{F M 3 W}(D)\right) \\
\vdots & \ddots & \vdots \\
\left(\mu_{F M_{n} W}(O), v_{F M_{n} W}(O), \pi_{F M_{n} W}(O)\right) & \left(\mu_{F M_{n} W}(S), v_{F M_{n} W}(S), \pi_{F M_{n} W}(S)\right) & \left(\mu_{F M_{n} W}(D), v_{F M_{n} W}(D), \pi_{F M_{n} W}(D)\right)
\end{array}\right] \\
& \rightarrow\left[\begin{array}{ccc}
r_{1 O}^{\prime} & r_{1 S}^{\prime} & r_{1 D}^{\prime} \\
r_{2 O}^{\prime} & r_{2 S}^{\prime} & r_{2 D}^{\prime} \\
r_{3 O}^{\prime} & r_{3 S}^{\prime} & r_{3 D}^{\prime} \\
\vdots & \ddots & \vdots \\
r_{n O}^{\prime} & r_{n S}^{\prime} & r_{n D}^{\prime}
\end{array}\right]
\end{aligned}
$$

Where, $r_{i j}^{\prime}=\left(\mu_{i j}^{\prime}, v_{i j}^{\prime}, \pi_{i j}^{\prime}\right)=\left(\mu_{F M W}(c), v_{F M W}(c), \pi_{F M W}(c)\right)$ refers to the elements of aggregated intuitionistic fuzzy weighted matrix.

\section{Step 5: Determining the intuitionistic fuzzy positive-ideal and negative-ideal values}

Suppose that $J_{1}$ and $J_{2}$ are profit-type criterion and cost-type criterion, respectively. $F M^{+}$and $F M^{-}$are, respectively, intuitionistic fuzzy positive-ideal solution and intuitionistic fuzzy negative-ideal solution. Then $F M^{+}$and $F M^{-}$are obtained as follows:

$$
\begin{aligned}
& F M^{+}=\left(\mu_{F M^{+} W}\left(c_{j}\right), v_{F M^{+} W}\left(c_{j}\right)\right) \\
& F M^{-}=\left(\mu_{F M^{-} W}\left(c_{j}\right), v_{F M^{-} W}\left(c_{j}\right)\right)
\end{aligned}
$$

Then,

$$
\begin{aligned}
& \mu_{F M^{+} W}\left(c_{j}\right)=\left(\left\langle\max _{i} \mu_{F M_{i} W}\left(c_{j}\right) \mid j \in J_{1}\right\rangle,\left\langle\min _{i} \mu_{F M_{i} \cdot W}\left(c_{j}\right) \mid j \in J_{2}\right\rangle\right) \\
& v_{F M^{+} W}\left(c_{j}\right)=\left(\left\langle\min _{i} v_{F M_{i} \cdot W}\left(c_{j}\right) \mid j \in J_{1}\right\rangle,\left\langle\max _{i} v_{F M_{i} \cdot W}\left(c_{j}\right) \mid j \in J_{2}\right\rangle\right) \\
& \mu_{F M^{-} W}\left(c_{j}\right)=\left(\left\langle\min _{i} \mu_{F M_{i} \cdot W}\left(c_{j}\right) \mid j \in J_{1}\right\rangle,\left\langle\max _{i} \mu_{F M_{i} \cdot W}\left(c_{j}\right) \mid j \in J_{2}\right\rangle\right) \\
& v_{F M^{-} W}\left(c_{j}\right)=\left(\left\langle\max _{i} v_{F M_{i} \cdot W}\left(c_{j}\right) \mid j \in J_{1}\right\rangle,\left\langle\min _{i} v_{F M_{i} \cdot W}\left(c_{j}\right) \mid j \in J_{2}\right\rangle\right)
\end{aligned}
$$


Step 6: Calculating the distance between failure items and positive and negative ideals Various methods have been proposed (Atanassov 1999; Grzegorzewski 2004; Szmidt and Kacprzyk 2000), e.g. Hamming distance, Euclidean distance and their normalized distance to calculate the distance between two intuitionistic fuzzy numbers. The distance from the $i$ th failure item to positive and negative ideals is shown as, respectively $S^{+}$and $S^{-}$. In this study, normalized Euclidean distance (Szmidt and Kacprzyk 2000) is used to evaluate the aforementioned distances as follows:

$$
\begin{aligned}
& S^{+}=\sqrt{\frac{1}{2 n} \sum_{j=1}^{n}\left[\left(\mu_{F M_{i} \cdot W}\left(c_{j}\right)-\mu_{F M^{+} W}\left(c_{j}\right)\right)^{2}+\left(v_{F M_{i} \cdot W}\left(c_{j}\right)-v_{F M^{+} W}\left(c_{j}\right)\right)^{2}+\left(\pi_{F M_{i} \cdot W}\left(c_{j}\right)-\pi_{F M^{+} W}\left(c_{j}\right)\right)^{2}\right]} \\
& S^{-}=\sqrt{\frac{1}{2 n} \sum_{j=1}^{n}\left[\left(\mu_{F M_{i} \cdot W}\left(c_{j}\right)-\mu_{F M^{-} W}\left(c_{j}\right)\right)^{2}+\left(v_{F M_{i} W}\left(c_{j}\right)-v_{F M^{-} W}\left(c_{j}\right)\right)^{2}+\left(\pi_{F M_{i} \cdot W}\left(c_{j}\right)-\pi_{F M^{-} W}\left(c_{j}\right)\right)^{2}\right]}
\end{aligned}
$$

\section{Step 7: Calculating the relative closeness coefficient to intuitionistic ideal}

The relative closeness coefficient of failure item $F M_{i}$ is defined according to the intuitionistic fuzzy positive-ideal solution $\mathrm{FM}^{+}$:

$$
C_{i^{+}}=\frac{S_{i^{-}}}{S_{i^{+}}+S_{i^{-}}} \quad, \quad 0 \leq C_{i^{+}} \leq 1
$$

\section{Step 8: Ranking the failure items}

After determining the relative closeness coefficient for each of the failure items, the latter could be ranked in descending order based on the values $C_{i^{+}}$. In other words, the failure item with a larger $C_{i^{+}}$is placed in higher priority.

\section{RESULTS}

This section presents the findings from the failure items evaluation of library service quality improvement based on the proposed model. The present study used the international LibQUAL questionnaire. Numerous studies have been conducted on the service quality assessment using the LibQUAL model. These studies provide reports on the use of LibQUAL model in a variety of libraries and measure library users' satisfaction with services (Hebert 1994; Dole 2002; Hichingham and Kenney 2002; Probst 2004; Feather 2005; Kyrillidou and Persson 2006; Thompson, Kyrillidou and Cook 2007; Kalb 2007; Jaggars, Jaggars and Duffy 2009).

The proposed model was implemented at Yazd University of Science and Art in Iran. Based on the earlier studies and a university experts' survey, a total of 25 failure items was determined for library service quality improvement (Table 2). After determining the items of libraries service quality improvement, the research questionnaires were developed and distributed among the experts. The results obtained from the evaluation of library service quality improvement items based on the comments made by 4 experts are presented in Table 3. The results are obtained based on the conversion of verbal expressions (see Table 1) into the corresponding intuitionistic fuzzy numbers. 
Table 2: Failure Items of Library Service Quality

\begin{tabular}{|c|c|}
\hline \multicolumn{2}{|r|}{ Failure Items } \\
\hline $\mathrm{A}_{1}$ & Lack of induced trust and confidence on users by library staff \\
\hline $\mathrm{A}_{2}$ & Staff lack of preparedness to respond the users' questions \\
\hline$A_{3}$ & Lack of passion and interest in staff to help users \\
\hline $\mathrm{A}_{4}$ & Staff lack of interest to solve the problems of users \\
\hline$A_{5}$ & Lack of attention, particularly to users \\
\hline$A_{6}$ & Lack of staff with sufficient knowledge to respond the questions posed by the users \\
\hline $\mathrm{A}_{7}$ & Lack of polite treatment on behalf of staff with users \\
\hline $\mathrm{A}_{8}$ & Inappropriate and non-compassionate behavior of staff in solving the problems of users \\
\hline A9 & Staff lack of understanding of the needs of users \\
\hline$\overline{A_{10}}$ & Lack of tranquil space for individual activities \\
\hline $\mathrm{A}_{11}$ & Lack of a comfortable and attractive place \\
\hline $\mathrm{A}_{12}$ & Inappropriate atmosphere of libraries that fail to induce the sense of study or learning \\
\hline $\mathrm{A}_{13}$ & Lack of appropriate social space for group learning and study \\
\hline $\mathrm{A}_{14}$ & Inappropriate environment of libraries for study, learning, and research \\
\hline $\mathrm{A}_{15}$ & Lack of access to sets of printed and electronic journal required for users \\
\hline $\mathrm{A}_{16}$ & Lack of sufficient and available books, dissertations, and other printer resources required by users \\
\hline $\mathrm{A}_{17}$ & Lack of access to electronic resources required by users \\
\hline$A_{18}$ & $\begin{array}{l}\text { Lack of appropriate place to borrow book, journal, and other printer resources from other } \\
\text { libraries }\end{array}$ \\
\hline $\mathrm{A}_{19}$ & Difficult access to collection sets of libraries \\
\hline $\mathrm{A}_{20}$ & Lack of easy to use used tools to access the required information \\
\hline $\mathrm{A}_{21}$ & Lack of a website to allow the rapid access to required information \\
\hline $\mathrm{A}_{22}$ & Lack of access to modern equipment and facilities providing easy access to required information \\
\hline $\mathrm{A}_{23}$ & Lack of required information to be independently accessed by guest students \\
\hline 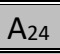 & Lack of access to electronic resources from home or workplace \\
\hline $\mathrm{A}_{25}$ & Incompatibility of libraries working hours with the users' needs \\
\hline
\end{tabular}

Table 3: Evaluation of the Failure Items of Library Service Quality by IFS

\begin{tabular}{|c|c|c|c|c|c|c|c|}
\hline \multirow{2}{*}{ Items } & \multicolumn{3}{|c|}{$D_{1}$} & \multirow{2}{*}{ Items } & \multicolumn{3}{|c|}{$D_{2}$} \\
\hline & $\mathrm{O}$ & $S$ & D & & $\mathrm{O}$ & $S$ & D \\
\hline$A_{1}$ & $(0.9,0.1,0)$ & $(1,0,0)$ & $(1,0,0)$ & $A_{1}$ & $(0.1,0.9,0)$ & $(0.25,0.6,0.15)$ & $(0.1,0.75,0.15)$ \\
\hline$A_{2}$ & $(0.5,0.45,0.05)$ & $(0.9,0.1,0)$ & $(0.6,0.3,0.1)$ & $A_{2}$ & $(0.9,0.1,0)$ & $(0.8,0.1,0.1)$ & $(1,0,0)$ \\
\hline$A_{3}$ & $(0.75,0.2,0.05)$ & $(0.7,0.2,0.1)$ & $(0.9,0.1,0)$ & $A_{3}$ & $(0.35,0.6,0.05)$ & $(0.1,0.75,0.15)$ & $(0.9,0.1,0)$ \\
\hline $\mathrm{A}_{4}$ & $(0.9,0.1,0)$ & $(0.7,0.2,0.1)$ & $(0.7,0.2,0.1)$ & $\mathrm{A}_{4}$ & $(0.1,0.9,0)$ & $(0.1,0.9,0)$ & $(0.8,0.1,0.1)$ \\
\hline $\mathrm{A}_{5}$ & $(0.5,0.45,0.05)$ & $(0.6,0.3,0.1)$ & $(0.8,0.1,0.1)$ & $\mathrm{A}_{5}$ & $(0.75,0.2,0.05)$ & $(0.5,0.4,0.1)$ & $(0.6,0.3,0.1)$ \\
\hline$A_{6}$ & $(0.35,0.6,0.05)$ & $(0.6,0.3,0.1)$ & $(0.6,0.3,0.1)$ & $A_{6}$ & $(0.1,0.9,0)$ & $(1,0,0)$ & $(0.4,0.5,0.1)$ \\
\hline$A_{7}$ & $(0.75,0.2,0.05)$ & $(0.8,0.1,0.1)$ & $(1,0,0)$ & $A_{7}$ & $(0.35,0.6,0.05)$ & $(0.6,0.3,0.1)$ & $(0.1,0.75,0.15)$ \\
\hline$A_{8}$ & $(0.5,0.45,0.05)$ & $(1,0,0)$ & $(0.5,0.4,0.1)$ & $A_{8}$ & $(0.9,0.1,0)$ & $(0.4,0.5,0.1)$ & $(0.6,0.3,0.1)$ \\
\hline $\mathrm{A}_{9}$ & $(0.75,0.2,0.05)$ & $(0.6,0.3,0.1)$ & $(0.9,0.1,0)$ & $A_{9}$ & $(0.1,0.9,0)$ & $(0.7,0.2,0.1)$ & $(0.1,0.9,0)$ \\
\hline$A_{10}$ & $(0.9,0.1,0)$ & $(0.7,0.2,0.1)$ & $(0.4,0.5,0.1)$ & $A_{10}$ & $(0.5,0.45,0.05)$ & $(1,0,0)$ & $(0.8,0.1,0.1)$ \\
\hline$A_{11}$ & $(0.1,0.9,0)$ & $(0.8,0.1,0.1)$ & $(0.9,0.1,0)$ & $A_{11}$ & $(0.5,0.45,0.05)$ & $(0.9,0.1,0)$ & $(0.7,0.2,0.1)$ \\
\hline$A_{12}$ & $(0.1,0.9,0)$ & $(0.9,0.1,0)$ & $(1,0,0)$ & $A_{12}$ & $(0.5,0.45,0.05)$ & $(0.1,0.9,0)$ & $(1,0,0)$ \\
\hline $\mathrm{A}_{13}$ & $(0.9,0.1,0)$ & $(1,0,0)$ & $(0.9,0.1,0)$ & $\mathrm{A}_{13}$ & $(0.5,0.45,0.05)$ & $(0.1,0.9,0)$ & $(0.5,0.4,0.1)$ \\
\hline
\end{tabular}


Tooranloo, H.S., Ayatollah, A.S., \& Marvasti, M. T.

\begin{tabular}{|c|c|c|c|c|c|c|c|}
\hline $\mathrm{A}_{14}$ & $(0.1,0.9,0)$ & $(0.6,0.3,0.1)$ & $(0.4,0.5,0.1)$ & $\mathrm{A}_{14}$ & $(0.5,0.45,0.05)$ & $(0.25,0.6,0.15)$ & $(0.1,0.75,0.15)$ \\
\hline $\mathrm{A}_{15}$ & $(0.5,0.45,0.05)$ & $(0.8,0.1,0.1)$ & $(0.8,0.1,0.1)$ & $A_{15}$ & $(0.35,0.6,0.05)$ & $(0.8,0.1,0.1)$ & $(0.25,0.6,0.15)$ \\
\hline$A_{16}$ & $(0.1,0.9,0)$ & $(0.5,0.4,0.1)$ & $(0.5,0.4,0.1)$ & $A_{16}$ & $(0.75,0.2,0.05)$ & $(0.4,0.5,0.1)$ & $(0.9,0.1,0)$ \\
\hline$A_{17}$ & $(0.75,0.2,0.05)$ & $(0.6,0.3,0.1)$ & $(0.1,0.75,0.15)$ & $A_{17}$ & $(0.5,0.45,0.05)$ & $(0.6,0.3,0.1)$ & $(0.1,0.9,0)$ \\
\hline $\mathrm{A}_{18}$ & $(0.35,0.6,0.05)$ & $(0.25,0.6,0.15)$ & $(0.7,0.2,0.1)$ & $\mathrm{A}_{18}$ & $(0.1,0.9,0)$ & $(0.6,0.3,0.1)$ & $(0.6,0.3,0.1)$ \\
\hline$A_{19}$ & $(0.1,0.9,0)$ & $(0.7,0.2,0.1)$ & $(0.8,0.1,0.1)$ & $A_{19}$ & $(0.5,0.45,0.05)$ & $(0.6,0.3,0.1)$ & $(0.7,0.2,0.1)$ \\
\hline$A_{20}$ & $(0.1,0.9,0)$ & $(0.7,0.2,0.1)$ & $(0.25,0.6,0.15)$ & $A_{20}$ & $(0.5,0.45,0.05)$ & $(0.9,0.1,0)$ & $(0.1,0.9,0)$ \\
\hline$A_{21}$ & $(0.1,0.9,0)$ & $(0.4,0.5,0.1)$ & $(0.7,0.2,0.1)$ & $A_{21}$ & $(0.9,0.1,0)$ & $(0.7,0.2,0.1)$ & $(0.7,0.2,0.1)$ \\
\hline$A_{22}$ & $(0.9,0.1,0)$ & $(1,0,0)$ & $(1,0,0)$ & $A_{22}$ & $(0.35,0.6,0.05)$ & $(0.5,0.4,0.1)$ & $(0.5,0.4,0.1)$ \\
\hline $\mathrm{A}_{23}$ & $(0.75,0.2,0.05)$ & $(0.8,0.1,0.1)$ & $(0.6,0.3,0.1)$ & $A_{23}$ & $(0.5,0.45,0.05)$ & $(0.6,0.3,0.1)$ & $(0.8,0.1,0.1)$ \\
\hline$A_{24}$ & $(0.5,0.45,0.05)$ & $(0.25,0.6,0.15)$ & $(0.1,0.75,0.15)$ & $A_{24}$ & $(0.75,0.2,0.05)$ & $(1,0,0)$ & $(1,0,0)$ \\
\hline$A_{25}$ & $(0.1,0.9,0)$ & $(0.9,0.1,0)$ & $(0.7,0.2,0.1)$ & $A_{25}$ & $(0.1,0.9,0)$ & $(0.25,0.6,0.15)$ & $(0.1,0.75,0.15)$ \\
\hline \multirow{2}{*}{ Items } & \multicolumn{3}{|c|}{$\mathrm{D}_{3}$} & \multirow{2}{*}{ Items } & \multicolumn{3}{|c|}{$\mathrm{D}_{4}$} \\
\hline & 0 & S & D & & 0 & S & D \\
\hline$A_{1}$ & $(0.75,0.2,0.05)$ & $(1,0,0)$ & $(0.5,0.4,0.1)$ & $A_{1}$ & $(0.5,0.45,0.05)$ & $(0.4,0.5,0.1)$ & $(0.1,0.9,0)$ \\
\hline$A_{2}$ & $(0.5,0.45,0.05)$ & $(0.7,0.2,0.1)$ & $(0.5,0.4,0.1)$ & $A_{2}$ & $(0.5,0.45,0.05)$ & $(1,0,0)$ & $(0.6,0.3,0.1)$ \\
\hline$A_{3}$ & $(0.5,0.45,0.05)$ & $(0.6,0.3,0.1)$ & $(0.5,0.4,0.1)$ & $\mathrm{A}_{3}$ & $(0.75,0.2,0.05)$ & $(0.8,0.1,0.1)$ & $(0.1,0.75,0.15)$ \\
\hline $\mathrm{A}_{4}$ & $(0.35,0.6,0.05)$ & $(0.8,0.1,0.1)$ & $(0.6,0.3,0.1)$ & $\mathrm{A}_{4}$ & $(0.35,0.6,0.05)$ & $(0.6,0.3,0.1)$ & $(0.7,0.2,0.1)$ \\
\hline$A_{5}$ & $(0.9,0.1,0)$ & $(0.1,0.9,0)$ & $(0.8,0.1,0.1)$ & $\mathrm{A}_{5}$ & $(0.9,0.1,0)$ & $(0.9,0.1,0)$ & $(0.8,0.1,0.1)$ \\
\hline$A_{6}$ & $(0.5,0.45,0.05)$ & $(0.25,0.6,0.15)$ & $(0.9,0.1,0)$ & $A_{6}$ & $(0.9,0$ & $(0.1,0.75,0.15)$ & $(0.25,0.6,0.15)$ \\
\hline$A_{7}$ & $(0.1,0.9,0)$ & $(0.1,0.75,0.15)$ & $(0.25,0.6,0.15)$ & $A_{7}$ & $(0.5,0.45,0.05)$ & $(0.5,0.4,0.1)$ & $(0.5,0.4,0.1)$ \\
\hline$A_{8}$ & $(0.5,0.45,0.05)$ & $(0.5,0.4,0.1)$ & $(0.5,0.4,0.1)$ & $A_{8}$ & $(0.5,0.45,0.05)$ & $(0.25,0.6,0.15)$ & $(0.9,0.1,0)$ \\
\hline$A_{9}$ & $(0.5,0.45,0.05)$ & $(0.4,0.5,0.1)$ & $(0.6,0.3,0.1)$ & $A_{9}$ & $(0.1,0.9,0)$ & $(0.7,0.2,0.1)$ & $(0.4,0.5,0.1)$ \\
\hline $\mathrm{A}_{10}$ & $(0.5,0.45,0.05)$ & $(0.4,0.5,0.1)$ & $(0.1,0.75,0.15)$ & $A_{10}$ & $(0.75,0.2,0.05)$ & $(0.6,0.3,0.1)$ & $(1,0,0)$ \\
\hline$A_{11}$ & $(0.75,0.2,0.05)$ & $(0.5,0.4,0.1)$ & $(0.7,0.2,0.1)$ & $A_{11}$ & $(0.9,0.1,0)$ & $(0.5,0.4,0.1)$ & $(0.6,0.3,0.1)$ \\
\hline $\mathrm{A}_{12}$ & $(0.9,0.1,0)$ & $(0.1,0.9,0)$ & $(0.1,0.9,0)$ & $\mathrm{A}_{12}$ & $(0.5,0.45,0.05)$ & $(0.6,0.3,0.1)$ & $(1,0,0)$ \\
\hline $\mathrm{A}_{13}$ & $(0.9,0.1,0)$ & $(1,0,0)$ & $(0.7,0.2,0.1)$ & $A_{13}$ & $(0.5,0.45,0.05)$ & $(0.9,0.1,0)$ & $(0.1,0.9,0)$ \\
\hline $\mathrm{A}_{14}$ & $(0.5,0.45,0.05)$ & $(0.1,0.9,0)$ & $(0.1,0.9,0)$ & $\mathrm{A}_{14}$ & $(0.5,0.45,0.05)$ & $(1,0,0)$ & $(0.1,0.75,0.15)$ \\
\hline$A_{15}$ & $(0.5,0.45,0.05)$ & $(0.6,0.3,0.1)$ & $(1,0,0)$ & $A_{15}$ & $(0.1,0.9,0)$ & $(0.6,0.3,0.1)$ & $(0.25,0.6,0.15)$ \\
\hline$A_{16}$ & $(0.1,0.9,0)$ & ח & $(0.4,0.5,0.1)$ & $A_{16}$ & $(0.75,0.2,0.05)$ & $(0.6,0.3,0.1)$ & $(0.7,0.2,0.1)$ \\
\hline$A_{17}$ & $(0.1,0.9,0)$ & $(0.1,0.9,0)$ & $(0.4,0.5,0.1)$ & $A_{17}$ & $(0.5,0.45,0.05)$ & $(0.7,0.2,0.1)$ & $(0.9,0.1,0)$ \\
\hline$A_{18}$ & $(0.35,0.6,0.05)$ & $(0.8,0.1,0.1)$ & $(0.6,0.3,0.1)$ & $A_{18}$ & $(0.35,0.6,0.05)$ & $(0.6,0.3,0.1)$ & $(0.6,0.3,0.1)$ \\
\hline $\mathrm{A}_{19}$ & $(0.75,0.2,0.05)$ & $(0.1,0.9,0)$ & $(0.25,0.6,0.15)$ & $\mathrm{A}_{19}$ & $(0.5,0.45,0.05)$ & $(0.8,0.1,0.1)$ & $(0.8,0.1,0.1)$ \\
\hline$A_{20}$ & $(0.5,0.45,0.05)$ & $(0.1,0.75,0.15)$ & $(0.8,0.1,0.1)$ & $A_{20}$ & $(0.35,0.6,0.05)$ & $(0.1,0.75,0.15)$ & $(0.25,0.6,0.15)$ \\
\hline$A_{21}$ & $(0.5,0.45,0.05)$ & $(0.7,0.2,0.1)$ & $(0.5,0.4,0.1)$ & $A_{21}$ & $(0.35,0.6,0.05)$ & $(0.4,0.5,0.1)$ & $(0.25,0.6,0.15)$ \\
\hline$A_{22}$ & $(0.1,0.9,0)$ & $(0.1,0.75,0.15)$ & $(0.4,0.5,0.1)$ & $A_{22}$ & $(0.75,0.2,0.05)$ & $(0.9,0.1,0)$ & $(0.1,0.9,0)$ \\
\hline $\mathrm{A}_{23}$ & $(0.9,0.1,0)$ & $(0.1,0.9,0)$ & $(0.9,0.1,0)$ & $A_{23}$ & $(0.9,0.1,0)$ & $(1,0,0)$ & $(0.6,0.3,0.1)$ \\
\hline$A_{24}$ & $(0.5,0.45,0.05)$ & $(0.7,0.2,0.1)$ & $(0.7,0.2,0.1)$ & $A_{24}$ & $(0.5,0.45,0.05)$ & $(0.6,0.3,0.1)$ & $(0.7,0.2,0.1)$ \\
\hline$A_{25}$ & $(0.75,0.2,0.05)$ & $(1,0,0)$ & $(0.5,0.4,0.1)$ & $A_{25}$ & $(0.5,0.45,0.05)$ & $(0.4,0.5,0.1)$ & $(0.1,0.9,0)$ \\
\hline
\end{tabular}

\section{Step 1: Determining the weights of decision makers (DMs)}

According to equation (11), the values $\lambda_{k}$ for each decision maker are determined as follows: 


$$
\lambda_{k}=\left|\begin{array}{cccc}
K_{1} & K_{2} & K_{3} & K_{4} \\
0.299 & 0.175 & 0.263 & 0.263
\end{array}\right|
$$

Step 2: Constructing the aggregated intuitionistic fuzzy decision matrix based on the opinions of DMs

According to the weights obtained for each decision maker and given the equation (12), aggregated decision makers' opinion matrix $r_{i j}$ is determined as presented in Table 4 .

Table 4: Aggregated Decision Makers' Opinion $r_{i j}$

\begin{tabular}{|c|c|c|c|}
\hline Items & 0 & $S$ & $D$ \\
\hline$A_{1}$ & $(0.764,0.232,0.004)$ & $(1,0,0)$ & $(1,0,0)$ \\
\hline$A_{2}$ & $(0.538,0.41,0.051)$ & $(1,0,0)$ & $(0.395,0.507,0.098)$ \\
\hline$A_{3}$ & $(0.693,0.271,0.035)$ & $(1,0,0)$ & $(1,0,0)$ \\
\hline$A_{4}$ & $(0.73,0.244,0.026)$ & $(0.647,0.234,0.119)$ & $(0.622,0.301,0.077)$ \\
\hline$A_{5}$ & $(0.364,0.591,0.045)$ & $(0.616,0.272,0.112)$ & $(0.733,0.16,0.107)$ \\
\hline$A_{6}$ & $(0.795,0.193,0.013)$ & $(0.642,0.315,0.042)$ & $(0.722,0.168,0.109)$ \\
\hline$A_{7}$ & $(0.705,0.268,0.027)$ & $(1,0,0)$ & $(1,0,0)$ \\
\hline$A_{8}$ & $(0.389,0.568,0.043)$ & $(1,0,0)$ & $(0.383,0.497,0.12)$ \\
\hline$A_{9}$ & $(0.693,0.271,0.035)$ & $(0.463,0.425,0.113)$ & $(0.805,0.175,0.02)$ \\
\hline$A_{10}$ & $(0.6,0.389,0.011)$ & $(0.64,0.255,0.105)$ & $(0.421,0.485,0.094)$ \\
\hline$A_{11}$ & $(0.503,0.447,0.049)$ & $(1,0,0)$ & $(1,0,0)$ \\
\hline$A_{12}$ & $(0.675,0.301,0.024)$ & $(0.767,0.207,0.026)$ & $(1,0,0)$ \\
\hline$A_{13}$ & $(0.798,0.193,0.009)$ & $(1,0,0)$ & $(1,0,0)$ \\
\hline$A_{14}$ & $(0.61,0.373,0.018)$ & $(1,0,0)$ & $(0.461,0.441,0.098)$ \\
\hline$A_{15}$ & $(0.5,0.45,0.05)$ & $(1,0,0)$ & $(0.426,0.431,0.143)$ \\
\hline$A_{16}$ & $(0.272,0.699,0.03)$ & $(0.621,0.27,0.109)$ & $(1,0,0)$ \\
\hline$A_{17}$ & $(0.65,0.297,0.053)$ & $(0.702,0.246,0.052)$ & $(0.587,0.335,0.078)$ \\
\hline$A_{18}$ & $(0.369,0.588,0.043)$ & $(0.446,0.443,0.111)$ & $(0.673,0.276,0.051)$ \\
\hline$A_{19}$ & $(0.242,0.727,0.031)$ & $(0.694,0.199,0.107)$ & $(0.675,0.216,0.109)$ \\
\hline$A_{20}$ & $(0.503,0.447,0.049)$ & $(0.621,0.266,0.113)$ & $(0.549,0.309,0.142)$ \\
\hline$A_{21}$ & $(0.361,0.597,0.042)$ & $(0.457,0.467,0.076)$ & $(0.584,0.29,0.126)$ \\
\hline$A_{22}$ & $(0.75,0.238,0.012)$ & $(1,0,0)$ & $(1,0,0)$ \\
\hline$A_{23}$ & $(0.586,0.36,0.054)$ & $(0.709,0.217,0.074)$ & $(0.427,0.482,0.091)$ \\
\hline$A_{24}$ & $(0.786,0.204,0.01)$ & $(1,0,0)$ & $(0.686,0.244,0.07)$ \\
\hline$A_{25}$ & $(0.472,0.48,0.048)$ & $(1,0,0)$ & $(1,0,0)$ \\
\hline & & & \\
\hline & & & \\
\hline & & & \\
\hline
\end{tabular}

Step 3: Determining the weights of risk factors

According to the matrix presented in Table 4 and equation 13, the weights of all risk factors are determined as follows:

$$
W_{j}=\left|\begin{array}{ccc}
0 & \mathrm{~S} & \mathrm{D} \\
(0.794,0.188,0.018) & (0.831,0.156,0.013) & (0.764,0.206,0.029)
\end{array}\right|
$$


Tooranloo, H.S., Ayatollah, A.S., \& Marvasti, M. T.

The above-mentioned results indicate that the failure severity factor (S) has higher weight than two other factors.

\section{Step 4: Constructing the aggregated intuitionistic fuzzy weighted matrix}

Multiplying the weight vector of risk factors by matrix $r_{i j}$ based on equation (14) and (15), the aggregated intuitionistic fuzzy weighted matrix of the library service quality improvement items evaluation $R \otimes W$ is obtained as presented in Table 5.

Table 5: Aggregated Intuitionistic Fuzzy Weighted Matrix of Library Service Quality Improvement Items Evaluation $R \otimes W$

\begin{tabular}{|c|c|c|c|}
\hline Items & 0 & $\mathrm{~S}$ & $\mathrm{D}$ \\
\hline $\mathrm{A}_{1}$ & $(0.607,0.376,0.017)$ & $(0.831,0.156,0.013)$ & $(0.764,0.206,0.029)$ \\
\hline $\mathrm{A}_{2}$ & $(0.427,0.521,0.051)$ & $(0.831,0.156,0.013)$ & $(0.302,0.609,0.089)$ \\
\hline $\mathrm{A}_{3}$ & $(0.551,0.408,0.041)$ & $(0.831,0.156,0.013)$ & $(0.764,0.206,0.029)$ \\
\hline $\mathrm{A}_{4}$ & $(0.58,0.386,0.034)$ & $(0.538,0.353,0.108)$ & $(0.475,0.445,0.079)$ \\
\hline $\mathrm{A}_{5}$ & $(0.289,0.668,0.043)$ & $(0.512,0.386,0.102)$ & $(0.56,0.333,0.106)$ \\
\hline $\mathrm{A}_{6}$ & $(0.631,0.345,0.024)$ & $(0.534,0.422,0.044)$ & $(0.552,0.34,0.108)$ \\
\hline $\mathrm{A}_{7}$ & $(0.56,0.406,0.034)$ & $(0.831,0.156,0.013)$ & $(0.764,0.206,0.029)$ \\
\hline $\mathrm{A}_{8}$ & $(0.309,0.649,0.042)$ & $(0.831,0.156,0.013)$ & $(0.293,0.601,0.106)$ \\
\hline $\mathrm{A}_{9}$ & $(0.551,0.408,0.041)$ & $(0.385,0.514,0.101)$ & $(0.616,0.345,0.04)$ \\
\hline $\mathrm{A}_{10}$ & $(0.477,0.504,0.02)$ & $(0.532,0.371,0.097)$ & $(0.322,0.591,0.087)$ \\
\hline $\mathrm{A}_{11}$ & $(0.4,0.551,0.049)$ & $(0.831,0.156,0.013)$ & $(0.764,0.206,0.029)$ \\
\hline $\mathrm{A}_{12}$ & $(0.536,0.433,0.032)$ & $(0.638,0.331,0.031)$ & $(0.764,0.206,0.029)$ \\
\hline $\mathrm{A}_{13}$ & $(0.633,0.345,0.022)$ & $(0.831,0.156,0.013)$ & $(0.764,0.206,0.029)$ \\
\hline $\mathrm{A}_{14}$ & $(0.484,0.491,0.025)$ & $(0.831,0.156,0.013)$ & $(0.352,0.556,0.091)$ \\
\hline $\mathrm{A}_{15}$ & $(0.397,0.553,0.049)$ & $(0.831,0.156,0.013)$ & $(0.326,0.548,0.126)$ \\
\hline $\mathrm{A}_{16}$ & $(0.216,0.755,0.029)$ & $(0.516,0.384,0.1)$ & $(0.764,0.206,0.029)$ \\
\hline $\mathrm{A}_{17}$ & $(0.516,0.429,0.055)$ & $(0.583,0.363,0.053)$ & $(0.449,0.472,0.079)$ \\
\hline $\mathrm{A}_{18}$ & $(0.293,0.666,0.041)$ & $(0.371,0.53,0.099)$ & $(0.514,0.425,0.06)$ \\
\hline $\mathrm{A}_{19}$ & $(0.192,0.778,0.03)$ & $(0.577,0.324,0.099)$ & $(0.516,0.378,0.106)$ \\
\hline $\mathrm{A}_{20}$ & $(0.4,0.551,0.049)$ & $(0.517,0.38,0.103)$ & $(0.419,0.452,0.129)$ \\
\hline $\mathrm{A}_{21}$ & $(0.287,0.673,0.04)$ & $(0.38,0.55,0.07)$ & $(0.446,0.436,0.118)$ \\
\hline $\mathrm{A}_{22}$ & $(0.596,0.381,0.023)$ & $(0.831,0.156,0.013)$ & $(0.764,0.206,0.029)$ \\
\hline $\mathrm{A}_{23}$ & $(0.465,0.48,0.054)$ & $(0.59,0.339,0.071)$ & $(0.327,0.589,0.085)$ \\
\hline $\mathrm{A}_{24}$ & $(0.624,0.354,0.022)$ & $(0.831,0.156,0.013)$ & $(0.525,0.4,0.076)$ \\
\hline $\mathrm{A}_{25}$ & $(0.375,0.578,0.047)$ & $(0.831,0.156,0.013)$ & $(0.764,0.206,0.029)$ \\
\hline & & & \\
\hline
\end{tabular}

Step 5: Determining the intuitionistic fuzzy positive-ideal and negative-ideal values According to results presented in table 5 and given the equation (16)-(20), the positiveideal and negative-ideal values are determined as follows:$$
F M^{+}=\mid \begin{gathered}
0 \\
(0.633,0.345,0.022) \\
(0.192,0.778,0.03)
\end{gathered}
$$
$\mathrm{S}$
D
$(0.831,0.156,0.013) \quad(0.764,0.206,0.029)$
$(0.371,0.55,0.079)$
$(0.293,0.609,0.098)$ 
Step 6: Calculating the distance between the failure items of library service quality and positive and negative ideals and determining the relative closeness coefficient to the intuitionistic ideal

The equations (21) and (22) calculate the distance from each of the failure items of library service quality to positive and negative ideals, and also the value of closeness coefficient, as presented in Table 6 . Results in Table 6 indicate that Index A13 with a proximity coefficient of 1 is the most important cause of failure of library service quality from the respondents' perspective. Index A1 with a proximity coefficient of 0.962 is in second place after Index A13. Indices A18 and A21 are put in the ranks 24 and 25 with proximity coefficients 0.283 and 0.239 respectively.

Table 6: Results of Distance between the Failure Items of Library Service Quality and Positive and Negative Ideals

\begin{tabular}{|c|c|c|c|c|}
\hline & $S_{i}^{+}$ & $S_{i}^{-}$ & $C_{i}$ & Rank \\
\hline $\mathrm{A}_{1}$ & 0.017 & 0.427 & 0.962 & 2 \\
\hline $\mathrm{A}_{2}$ & 0.275 & 0.287 & 0.511 & 16 \\
\hline $\mathrm{A}_{3}$ & 0.043 & 0.414 & 0.906 & 5 \\
\hline $\mathrm{A}_{4}$ & 0.217 & 0.269 & 0.553 & 12 \\
\hline $\mathrm{A}_{5}$ & 0.274 & 0.19 & 0.409 & 20 \\
\hline $\mathrm{A}_{6}$ & 0.195 & 0.307 & 0.612 & 10 \\
\hline $\mathrm{A}_{7}$ & 0.039 & 0.415 & 0.914 & 4 \\
\hline $\mathrm{A}_{8}$ & 0.311 & 0.259 & 0.454 & 18 \\
\hline $\mathrm{A}_{9}$ & 0.254 & 0.272 & 0.517 & 14 \\
\hline $\mathrm{A}_{10}$ & 0.3 & 0.19 & 0.388 & 22 \\
\hline $\mathrm{A}_{11}$ & 0.128 & 0.378 & 0.747 & 6 \\
\hline $\mathrm{A}_{12}$ & 0.12 & 0.353 & 0.746 & 7 \\
\hline $\mathrm{A}_{13}$ & 0 & 0.437 & 1 & 1 \\
\hline $\mathrm{A}_{14}$ & 0.238 & 0.302 & 0.559 & 11 \\
\hline $\mathrm{A}_{15}$ & 0.264 & 0.28 & 0.515 & 15 \\
\hline $\mathrm{A}_{16}$ & 0.289 & 0.271 & 0.484 & 17 \\
\hline $\mathrm{A}_{17}$ & 0.224 & 0.242 & 0.519 & 13 \\
\hline $\mathrm{A}_{18}$ & 0.339 & 0.134 & 0.283 & 24 \\
\hline $\mathrm{A}_{19}$ & 0.311 & 0.181 & 0.368 & 23 \\
\hline $\mathrm{A}_{20}$ & 0.272 & 0.177 & 0.394 & 21 \\
\hline $\mathrm{A}_{21}$ & 0.354 & 0.111 & 0.239 & 25 \\
\hline $\mathrm{A}_{22}$ & 0.021 & 0.425 & 0.953 & 3 \\
\hline $\mathrm{A}_{23}$ & 0.284 & 0.208 & 0.423 & 19 \\
\hline $\mathrm{A}_{24}$ & 0.127 & 0.373 & 0.746 & 8 \\
\hline $\mathrm{A}_{25}$ & 0.143 & 0.373 & 0.723 & 9 \\
\hline & & & & \\
\hline
\end{tabular}

\section{DISCUSSION}

It is significantly important to measure service quality in libraries because high-quality libraries can facilitate the sustainable development process in countries. In this regard, the 
use of service quality assessment methods is also very important since it is possible that applied models are not responsive to compensation for library service quality. In general, there are a variety of applied criteria and also tools and techniques for measurement of service quality and customer satisfaction. The failure analysis technique and its effects are among these tools. Like all risk assessment methods, FMEA can identify and evaluate risks. FMEA has numerous applications. According to the history of using multi-criteria decisionmaking methods in risk assessment, these methods have been used alone or with other methods for risk assessment in various cases. The present study provided a model for failure finding and routing of library service quality improvement by an Intuitionistic fuzzy FMEA approach based on LibQUAL model. This model is a combination of the Landa and Intuitionistic Fuzzy TOPSIS methods. In the theory of Intuitionistic fuzzy sets, a membership and non-membership degree is attributed to each member, and thus the hesitation and ambiguity, which are always associated with decision making, are well induced to problems. This leads to a decision matrix with evaluations with higher degrees of certainty and validity, and consequently, a more efficient decision. On this basis, the present paper used the intuitionistic fuzzy numbers for failure finding and routing the library service quality improvement. A total of 25 failure items of library service quality improvement were thus evaluated based on the experts' opinions at Yazd University of Science and Arts. Considering that decision makers' opinions have different weights in decision making process, Landa method was used to find them, so that the experts' opinions were stated on the basis of verbal expressions, and then converted to intuitionistic fuzzy numbers, and eventually weight of each decision maker was calculated (Equation 11). Subsequently, the aggregate decision matrix was formed using the IFWA operator.

Weights of risk factors were measured by Equation (13) in order to overcome the traditional FMEA method shortcoming after forming this matrix, which considered equal weights for risk factors. In the next step, the weighted intuitionistic fuzzy aggregate matrix was formed by multiplying the weight vector of risk factors (obtained in the previous step) by the aggregate matrix. After formation of this matrix, the criteria such as the type of profit and cost were identified and the positive and negative values were calculated. Using the above-mentioned formula, we calculated the distance between failure items with positive and negative ideals and finally measure the relative proximity coefficient in terms of intuitionistic ideal. In the last step of calculating this combined model, failure items were descending ranked based on the relative proximity coefficient. In this ranking, the failure item with a larger relative proximity coefficient was ranked as the top priority. According to this ranking, item A13 "lack of a suitable social space for group learning (A13)" with a proximity coefficient of 1 was put in the first rank. In this regard, we could use strategies such as design of library space by creating a quiet space for individual activities, creating an atmosphere of inducing a sense of study and learning, allocation of a suitable place for users' group activities, research and collective learning, development of library interiors and allocation of a suitable space for creation of scientific groups for study and review of works. Furthermore, item A1 "lack of induced confidence and trust in consumers by library staff " was placed in the second priority. Accordingly, measures can be taken to inform the human resources of libraries about the technology-based achievements and relevant skills as well as employee training to obtain the ability to identify and explain users' needs. On the other hand, given the important role of human relationships in the service quality and optimal use of library facilities and services, librarians and other human resources in libraries should be sufficiently educated in this field in order to provide better services. According to the results of this study, it was observed that A22 "lack of access to modern equipment which allows easy access to necessary information" was put in the third rank of failure of library service quality improvement programs. Considering this item, the free 
Internet for researchers, and ordinary users' access to online resources, attraction of its revenues for library cost, and creation of websites in libraries, and awareness of library resources and information about new books via the Internet can be useful in solving problems in the library service quality improvement.

\section{CONCLUSION}

This study can become the basis for improving the library service quality. Therefore, the provided ranks can guide managers and decision makers. Application of the proposed research model in the intuitionistic fuzzy environment removes the existing ambiguity in qualitative assessment of failure items, and also considers real and natural business conditions which have largely the uncertainty and ambiguity. This leads to more appropriate and real decisions. Identification of the most critical failures in terms of risk priority can be also utilized in various areas of planning in accordance with different policies of organizations. In particular, libraries are generally affiliated with other institutions and are less active as independent and private entities; hence, their policies need to be consistent with policies of a parent organization.

Therefore, it is hoped that librarians will take steps towards provision of the ultimate service for users by awareness of their expectations and needs due to the provision of necessary facilities for provision of services. Therefore, if there is a shortage of quality of provided services for users, it is not due to the librarians' lack of awareness about users' needs, but it is because of other factors such as lack of facilities for right services. Therefore, library authorities can reduce this gap by taking advantage of this opportunity and creating necessary facilities for provision of appropriate services.

This study was conducted with the aim to identify failure factors of library services and provide a suitable solution to solve these problems in libraries of Yazd University of Science and Arts. Therefore, this study was geographically limited to Yazd province. It was also limited to libraries of University of Science and Arts in terms of studied population. In terms of analysis techniques, Landa and Intuitionistic Fuzzy TOPSIS methods were the only applied techniques. Therefore, this research can be investigated in other population by other decision making methods.

\section{ACKNOWLEDGEMENT}

This research received no specific grant from any funding agency in the public, commercial, or not-for profit sectors. 


\section{REFERENCES}

Association of Research Libraries / Texas A\&M University. 2003. LibQUAL+TM Spring 2003 Survey, Group results .Washington, DC: Association of Research Libraries.

Association of Research Libraries / Texas A\&M University. 2004. LibQUAL+TM Spring 2004 Survey, Group results .Washington, DC: Association of Research Libraries.

Association of Research Libraries / Texas A\&M University. 2006. LibQUAL+TM Spring 2006 Survey. Washington ,DC: Association of Research Libraries.

Atanassov, K. T. 1986. Intuitionistic fuzzy sets. Fuzzy Sets and Systems, Vol.20, no.1: 87-96.

Atanassov, K.T. 1983. Intuitionistic fuzzy sets. VII ITKR's Session, Sofia, Bulgarian.

Atanassov, K.T. 1989. More on intuitionistic fuzzy sets. Fuzzy Sets and Systems, Vol.33, no.1: $37-46$

Atanassov, K.T. 1999. Intuitionistic fuzzy sets. New York: Physica-Verlag, Heidelberg.

Atanassov, K.T. 2000. Two theorems for Intuitionistic fuzzy sets. Fuzzy sets and systems, Vol. 110: 267-269.

Atanassov., K.T., and Gargov., G. 1989. Interval-valued intuitionistic fuzzy sets, Fuzzy Sets and Systems, Vol. 31, no.3: 343-349.

Ban, A.I. 2006. Nearest interval approximation of an intuitionistic fuzzy number, In Computational Intelligence, Theory and Applications, Springer-Verlag, Berlin, Heidelberg, 229-240.

Bell, S. J., and Eisingerich, A. B. 2007. The paradox of customer education: Customer expertise and loyalty in the financial services industry. European Journal of Marketing, Vol. 41, no. (5/6): 466-486.

Bowles, J. B., and Peláez, C. E. 1995. Fuzzy logic prioritization of failures in a system failure mode, effects and criticality analysis. Reliability Engineering and System Safety, Vol.50: 203-213.

Braglia, M., Frosolini, M., and Montanari, R. 2003. Fuzzy TOPSIS approach for failure mode, effects and criticality analysis. International Journal of Quality and Reliability Engineering, Vol.19: 425-443.

Buhaescu, T. 1989. Some observations on intuitionistic fuzzy relations, Itinerant Seminar of Functional Equations, Approximation and Convexity, Cluj-Napoca, 111-118.

Chanamool, N., and Naenna, T. 2016. Fuzzy FMEA application to improve decision making process in an emergency department. Applied Soft Computing, Vol. 43: 441-453. Available at: http://dx.doi.org/10.1016/j.asoc.2016.01.007.

Chang, C. L., Wei, C. C. and Lee, Y. H. 1999. Failure mode and effects analysis using fuzzy method and grey theory. Kybernetes, Vol.28: 1072-1080.

Chen, L. H., and Ko, W. C. 2009. Fuzzy linear programming models for new product design using QFD with FMEA. Applied Mathematical Modelling. Vol.33, no.2: 633-647. doi:10.1016/ j.apm.2007.11.029.

Chen, T.Y., and Li, C.H. 2011. Objective weights with intuitionistic fuzzy entropy measures and computational experiment analysis. Applied Soft Computing, Vol.11, no.8: 54115423.

Cook, C. and Heath, F. M. 2001. Users' perceptions of library service quality: A LibQUAL+ qualitative study. Library Trends, Vol.49, no.4: 548-584.

Cook, C., Heath, F. M., and Thompson, B. 2003. "Zones of Tolerance" in perceptions of library service quality: A LibQUAL+ Study. portal: Libraries and the Academy, Vol.3, no.1: 113-123.

Daniela ,R., and Dosoinescu,O. 2004. The Adoption Electronic Banking Services in Developing Countries. Department of Business Information Systems. Bd Carol Jnr.22-35. 
de Brito, G. F., and Vergueiro, W. D. C. S. 2013. Quality evaluation of academic library: the LibQUAL ${ }^{\circledR}$ methodology and its perspectives of implementation in Brazil. Brazilian Journal of Informtion Science (BJIS), Vol.7: 25 -44.

De, S.K., Biswas, R. and Roy, A.R. 2000. Some operations on intuitionistic fuzzy sets. Fuzzy sets and Systems, Vol. 114, no.4: 477-484.

Deschrijver, G., and E.E. Kerre. 2002. On the relationship between intuitionistic fuzzy sets and some other extensions of fuzzy set theory, Journal of Fuzzy Mathematics, Vol. 10, no. 3: 711-724.

Deschrijver, G., Cornelis, C., and Kerre, E. E. 2004. On the representation of intuitionistic fuzzy t-norms and t-conorms. IEEE transactions on fuzzy systems, Vol.12, no.1: 45-61.

Dole W. 2002. Libqual+TM and the small Academic library. Performance Measurement and Metric 2002, Vol.3, no.2: 85-95 .

Eddy, M.A and Solomon, D. 2017. Leveraging librarian liaison expertise in a new consultancy role, The Journal of Academic Librarianship, Vol. 43, no.2: 121-127.

Feather, C. 2005. Review of LibQUAL Survey Responses at the Ohio State University Libraries in 2002, 2003, and 2005, available at: oaa.osu.edu/irp/lib_systems/SSAppendixF.pdf.

Filiz, Z. 2007. Service quality of university library: a survey amongst students at Osmangazi University and Anadolu University. İstanbul Üniversitesi iktisat Fakültesi Ekonometri ve istatistik Dergisi, Vol.5: 1-19.

Garcia, P. A. A., Schirru, R., and E Melo, P. F. F. 2005. A fuzzy data envelopment analysis approach for FMEA. Progress in Nuclear Energy, Vol.46, no.3-4: 359-373.

Garthwait, C., and Richardson, E.A. 2008. LibQUAL+ ${ }^{\mathrm{TM}}$ in a consortium: KLN's challenges and considerations. New Library World, Vol.109: 499-511.

Gau W L.,and Buehrer D J. 1993. Vague sets. IEEE Transactions on Systems, Man, and Cybernetics, Vol. 23: 610-614.

Godwin, P. 2005. London South Bank University, Share fair: ALA Conference Summer 2005. Available at: www.libqual.org.

Gupta, D. K., and Jambhekar, A. 2002. Which way do you want to serve your customers? Information outlook, Vol.6, no.7: 26-32.

Hebert F. 1994. Service quality: An unobtrusive investigation of interlibrary loan in large public libraries in Canada .Library and information Science Research, Vol. 16, no.1: 321 .

Hichingham E. and Kenney D. 2002. Extracting meaningful measures of user satisfaction from LibQual+TM for the University at Virginia tech. Performance Measurment and Metrics, Vol.3, no.2: 48-58 .

Jaggars, D. E., Jaggars, S. S., and Duffy, J. S. 2009. Comparing Service Priorities Between Staff and Users in Association of Research Libraries (ARL) Member Libraries. Portal: Libraries and the Academy,, Vol.9, no.4: 441-452.

Kalb, S. 2007. LibQUAL survey 2007 at Queen's University library: Analysis of results. Available at: library.queensu.ca/webir/libqual-2007/2007-LibQUAL-Report.pdf .

Kang, G-D., Jame, J., and Alexandris, K. 2002. Measurement of internal service quality: Application of the SERVQUAL battery to internal service quality, Managing Service Quality: An International Journal, Vol.12, no.5: 278-291.

Kayongo, J., and Jones, S. 2008. Faculty perception of information control using LibQUAL+ ${ }^{\mathrm{TM}}$ indicators. The Journal of Academic Librarianship, Vol. 34, no.2: 130-138.

Kumru, M., and Kumru, P. Y. 2013. Fuzzy FMEA application to improve purchasing process in a public hospital. Applied Soft Computing, Vol.13, no.1: 721-733.

Kutlu, A.C., and Ekmekcioglu, M. 2012. Fuzzy failure modes and effects analysis by using fuzzy TOPSIS-based fuzzy AHP. Expert Systems Application. Vol.39, no,1: 61-67. 
Kyrillidou, M. and Persson A.C. 2006. The new library user in Sweden: A LibQUAL study at Lund University. Performance Measurement and Metrics, Vol.7, no.1: 45-53.

Ladhari, R., and Morales, M. 2008. Perceived service quality, perceived value and recommendation: A study among Canadian public library users. Library Management, Vol.29, no.4/5: 352-366.

Lane, F. C., Anderson, B., Ponce, H. F., and Natesan, P. 2012. Factorial invariance of LibQUAL ${ }^{\circledast}$ as a measure of library service quality over time. Library \& Information Science Research, Vol.34, no.1: 22-30.

Lin, C. T., Chiu, H. and Chu, P. Y. 2006. Agility index in the supply chain. International Journal of Production Economics, Vol. 100, no.2: 285-299.

Miao, H, and Bassham, M.W. 2007. Embracing customer service in libraries. Library Management, Vol.28, no.1/2: 53-61.

Mirghafuri, H, and Makki, F. 2007. Evaluate if the service quality in school libraries . Library \& Information Quarterly, Vol.10, no.1: 61-78.

Park, J. H., Cho, H. J., and Kwun, Y. C. 2013. Extension of the VIKOR method to dynamic intuitionistic fuzzy multiple attribute decision making. Computers \& Mathematics with Applications, Vol.65, no.4: 731-744.

Park, J. H., Park, I. Y., Kwun, Y. C. and Tan, X. 2011. Extension of the TOPSIS method for decision making problems under interval-valued intuitionistic fuzzy environment. Applied Mathematical Modelling, Vol.35, no.5: 2544-2556.

Posey, J. A. 2009. Student perceptions and expectations of library services quality and user satisfaction at Walters State Community College. A dissertation submitted to East Tennessee State University.

Probst L. 2004. Penn State Libraries: LibQual survey executive summary, November 2004 [Online]. Available at: http://www. Libraries. Psu.edu/public services/reports/LibQual 2004 Executive Summary.pdf .

Rafie, M. and Namin, F.S. 2015. Prediction of subsidence risk by FMEA using artificial neural network and fuzzy inference system. International Journal of Mining Science and Technology, Vol.25, no.4: 655-663.

Roy, A., Khare, A., Liu, B. S., Hawkes, L. M. and Swiatek-Kelley, J. 2012. An investigation of affect of service using a LibQUAL+ ${ }^{\mathrm{TM}}$ survey and an experimental study. The Journal of Academic Librarianship, Vol.38, no.3: 153-160.

Scherrer, C. S., and Jacobson, S. 2002. New measures for new roles: defining and measuring the current practices of health sciences librarians. Journal of Medical Library Association, Vol.90: 164-172.

Sharma, J.C. 2001, Total quality management in library and information services, in Dhawan, S.M. (Ed.), Quest for Quality, Indian Library Association, New Delhi, 166-71.

Stephen, T. 2005. Academic library performance, quality and evaluation in UK and Europe. Paper presented at the Symposium on International developments in library assessment and opportunities for Greek libraries, Thessaloniki, Greece, June 14, 2005. [on-line]. Available at: www.libqual.org.

Stoyanova, D. 1993. More on Cartesian product over intuitionistic fuzzy sets, BUSEFAL, Vol. 54: 9-13.

Szmidt, E. and Kacprzyk, J. 2000. Distances between intuitionistic fuzzy sets, Fuzzy Sets and Systems, Vol. 114, no.3: 505-518.

Szmidt, E. and Kacprzyk, J. 2001. Entropy for intuitionistic fuzzy sets. Fuzzy Sets and Systems, Vol. 118, no 3: 467-477.

Thompson, B., Kyrillidou, M. and Cook, C. 2007. User library service expectations in health service vs. other settings: a LibQUAL+ ${ }^{\circledR}$ Study. Health Information Library Journal, Vol. 24, No.Suppl 1: 38-45. 
Thompson, B., Cook, C. and Kyrillidou, M. 2005. Concurrent validity of LibQUAL+ ${ }^{\mathrm{TM}}$ scores: what do LibQUAL+ ${ }^{\mathrm{TM}}$ scores measure? The Journal of Academic Librarianship, Vol.31, no.6: 517-522.

Uddin, K. R. and Khandakar, S. A. 2013. Customer service quality: A study on foreign banks operating in Bangladesh, Journal of Business Studies, Vol.34, no.2: 105-130.

Wang, Y. M., Chin, K. S., Poon, K. K. G. and Yang, J. B. 2009. Risk evaluation in failure mode and effects analysis using fuzzy weighted geometric mean. Expert Systems with Applications, Vol.36, no.2: 1195-1207.

William, S. 2005. Operation management. New York: McGraw-Hill.

Wu, J.-Z. and Zhang, Q. 2011. Multicriteria decision making method based on intuitionistic fuzzy weighted entropy. Expert Systems with Applications, Vol. 38, no.1: 916-922.

Zabed, A. S. and Shoeb, H. Z. 2009. Measuring service quality of a public university library in Bangladesh using SERVQUAL. Performance Measurement and Metrics, Vol.10, no.1: 17-32.

Zadeh, L.A. 1965. Fuzzy sets. Information and Control, Vol.8: 338-353.

Zhang, Q. S., Jiang, S., Jia, B. and Luo, S. 2010. Some information measures for intervalvalued intuitionistic fuzzy sets. Information Sciences, Vol. 180, no. 24: 5130-5145.

Zhao, X. and Wei, G. 2013. Some intuitionistic fuzzy Einstein hybrid aggregation operators and their application to multiple attribute decision making. Knowledge-Based Systems, Vol.37: 472-479. 